\title{
ELECTRIFICATION OF HYDRAULIC SYSTEMS USING HIGH- EFFICIENCY PERMAMENT MAGNET MOTORS
}

\author{
Pablo Castro Palavicino ${ }^{1 *}$, Bulent Sarlioglu ${ }^{1}$, Dheeraj Bobba ${ }^{1}$, Woongkul Lee ${ }^{1}$, Tatiana \\ Minav $^{2}$ \\ ${ }^{l}$ Wisconsin Electric Machines and Power Electronics Consortium (WEMPEC), University of Wisconsin-Madison, \\ WI, USA \\ ${ }^{2}$ Tampere University, Faculty of Engineering and Natural Sciences, IHA, Tampere, Finland \\ * Corresponding author: Tel.: +1 608262 2703; E-mail address: sarlioglu@wisc.edu
}

\begin{abstract}
In this paper, electrification of hydraulic systems is proposed using high-efficiency permanent magnet (PM) motors and wide bandgap power electronic drives. Direct driven hydraulics (DDH) is selected because of its higher efficiency compared to other conventional technologies such as valve-controlled systems. The DDH is directly driven by a servomotor. The ratings and design guidelines for a servomotor used in DDH applications are provided in this paper. Specifically, a surface permanent magnet synchronous machine (SPMSM) is designed. Finally, a state-of-the-art inverter using silicon carbide wide bandgap devices are designed for high performance operation.
\end{abstract}

Keywords: Direct driven hydraulics, Electrification, Electric motors, Hydraulic actuator, High efficiency, Permanent magnet synchronous machines

\section{INTRODUCTION}

Hydraulic systems are known for their capability of applying large forces with a fast response. The further electrification of hydraulic systems is becoming popular, mainly for increasing the system efficiency. These additional features are attractive in a high-performance application such as heavy-duty mobile or stationary applications.

Electrification of powertrains in off-road mobile applications has been extensively studied [1]. The next step for further improvements consists of the electrification of working hydraulics or implements. Regarding drivetrain systems, electrification can be done by connecting an engine to an electric generator. Thus, a generator provides power to a combination of converters feeding electric motors to drive hydraulic pumps, which complete the electrification of the implements or actuators of hydraulic system.

Many examples of engine/electric generator type of electrification have been reported in the literature $[1,2]$, where authors demonstrated improvements in both force/position response and efficiency.
Reduced energy consumption and higher efficiency are critical in electric and hybrid offroad mobile applications, such as construction equipment, forest, and mining machinery. The state-of-the-art research demonstrated that significant improvements to the system efficiency can be achieved by switching from valve-controlled to pump-controlled hydraulic systems. Moreover, using a variable speed electric drive with a fixed displacement pump allows further improvements in the hydraulics, making it more energy efficient [3-5].

To provide high-performance electrification to hydraulic systems, high torque-density electric machines are required. Surface permanent magnet synchronous machines (SPMSM), with fractional-slot concentric windings (FSCW) becomes a desirable candidate, due to their high efficiency and high-power density. The main goal of this paper is to design a high-performance and efficient electric drive for further electrification of working hydraulics in off-road machinery with pump-controlled systems such as direct-driven hydraulics (DDH). 


\section{HYDRAULICS ELECTRIFICATION}

In a traditional diesel operated mobile machinery, the energy available in fuel is converted to hydraulic through an internal combustion engine (ICE). In [6], an accurate description of the sources of energy losses in a typical hydraulic system were described. The diagram of Figure 1 depicts how losses are distributed in a conventional hydraulic system.

Based on Figure 1, it is possible to identify several opportunities for increasing the efficiency in hydraulic systems. Although several improvements have been made in the design of ICE and hydraulic components [6], many hydraulics based applications, such as excavators, offer opportunities to recover energy. Typically, in excavator applications there are plenty of possibilities for harvesting and storing the kinetic and potential energy, for example, when bringing down a heavy load on a bucket to the ground or during swing motion. A general diagram of how electrification can improve hydraulic systems is shown in Figure 2.

Several examples of energy savings by electrification have been reported in [1]. Most of the focus for energy saving was based on including electrical energy storage, such as batteries or super capacitors. Thus kinetic and potential energy can be recovered through electric drives. Companies have deployed commercial products with a combination of hydraulic and electric systems. Examples of these products can be found for Kobelco, Hitachi, Caterpillar, and Komatsu [1, 2]. Topologies combining hydraulic and electrical systems by several manufacturers are depicted in Figure 3.

In the academic side, in [7], energy recovery was proposed for electric hydraulic hybrid electric system by harvesting potential energy from the boom in an excavator. Other examples include the design of novel topologies as the one shown in [8], which combines closed-loop in a hydrostatic transmission circuit and a hydraulic accumulator for energy storage. Many of the efforts have been made in utilizing hydraulic accumulators to recover the potential and kinetic energy of the system. The hydraulic accumulator then drives an electric generator which store the energy in capacitors or batteries. Examples of hydraulic accumulators for energy saving are provided in [9-12].

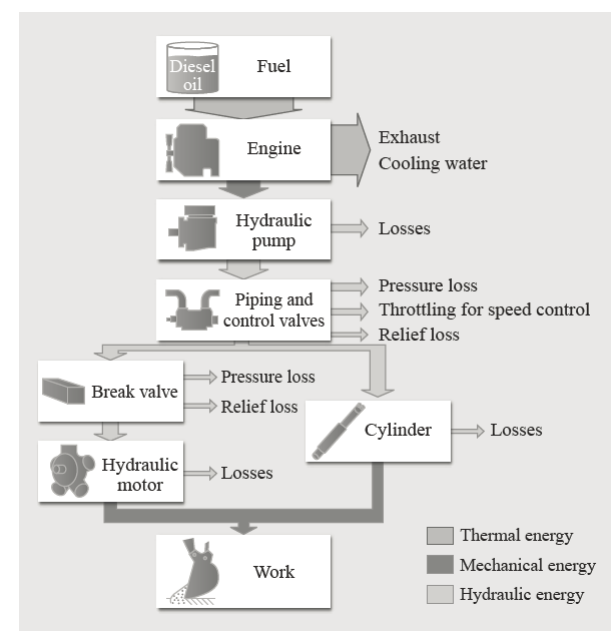

Figure 1: Power flow diagram for a hydraulic system depicting losses in the different stages of power conversion [6].

Industrial applications use open circuit hydraulic systems with large oil reservoirs with a valve to control flow, which is characterized by its low system efficiency. An alternative for valvecontrolled hydraulic system is directly applying power in the hydraulic pump and omitting complex servo valves. Thus, a prime mover is connected to the pump, resulting in pumpcontrolled systems [4]. In pump-controlled systems, a variable displacement pump is controlled by a prime mover. Thus, by running the electric motor at a fixed speed, the control of flow is performed by modifying the displacement of the pump. Therefore, less energy consumption can be achieved.

Further improvements can be made by utilizing an electric drive with variable speed to drive a fixed displacement pump. Thus, directly controlling the flow by modifying the speed of the electric motor. Systems, where a variable speed electric drive is used for directly operate a pump, are referred to as direct-driven hydraulic (DDH) systems [3-5, 13, 14]. A figure of a typical hydraulic system and DDH system is demonstrated in Figure 4 and Figure 5, respectively. By directly driving a pump, DDH systems become more efficient compared to their equivalent valve-controlled, thus improvements in efficiency up to $200 \%$ can be achieved. 


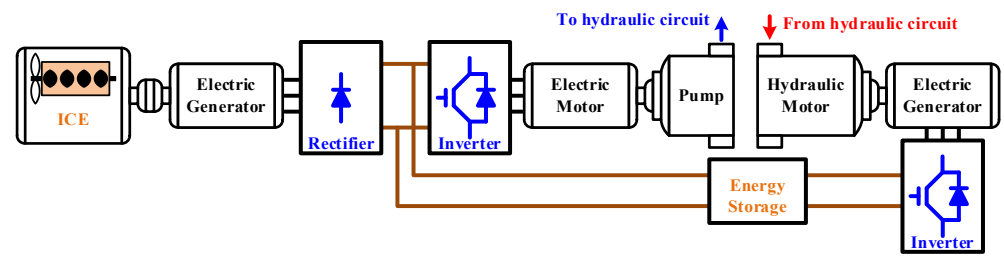

Figure 2: Generic scheme of how electrification allows to recover and store energy from hydraulic systems.

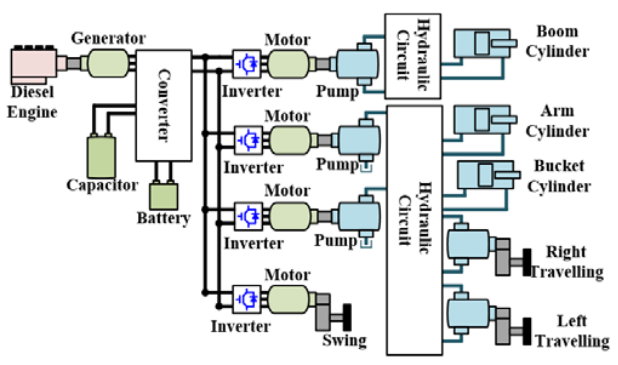

(a)

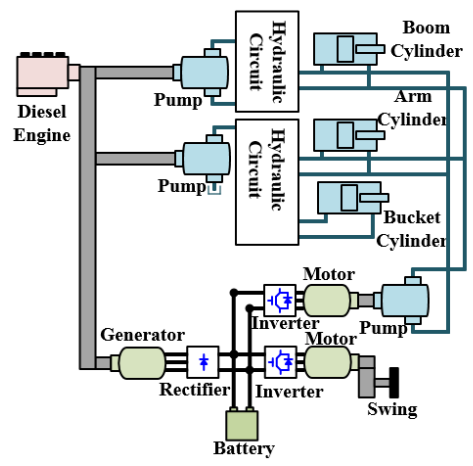

(c)

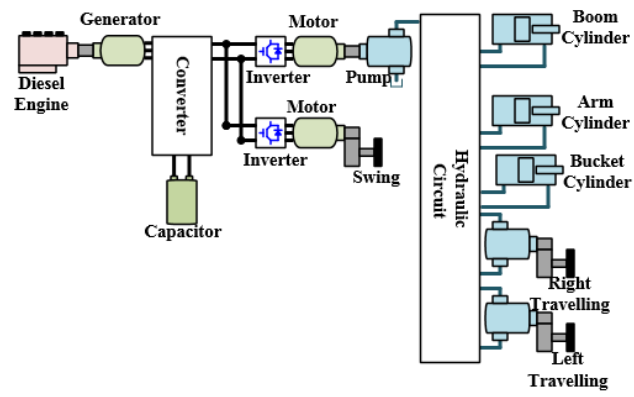

(e)

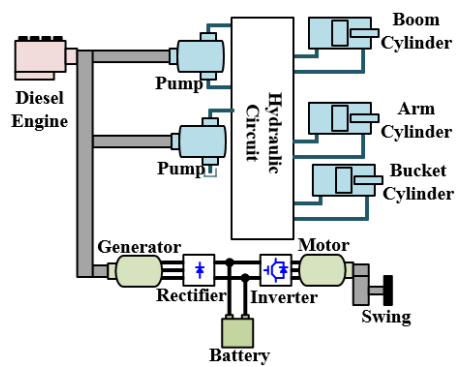

(b)

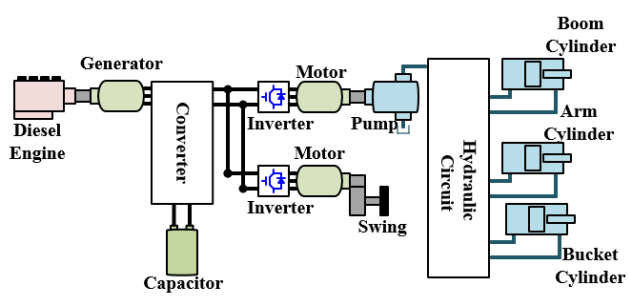

(d)

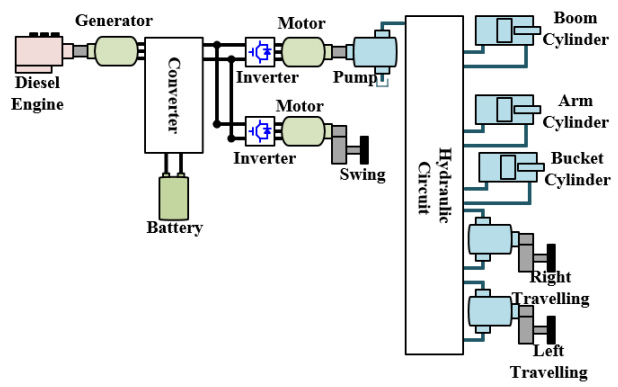

(f)

Figure 3: Examples of commercially available electrified excavators [1], (a) Kobe Steel series-parallel hybrid excavator, (b) Doosan series-parallel hybrid excavator, (c) Komatsu series-parallel hybrid excavator, (d) Hitachi parallel hybrid excavator, (e) New Holland parallel hybrid excavator, (f) Kobelco parallel hybrid excavator. 


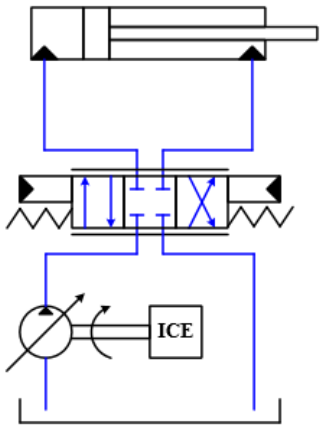

Figure 4: Simplified example of valve-controlled system.

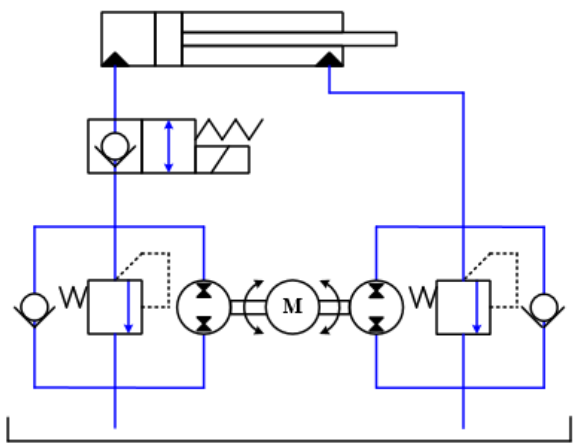

Figure 5: Direct driven hydraulic system.

Nowadays, electric drives can achieve a precise torque/speed/position control with minimal losses compared to hydraulic systems. One of the main objectives of this paper is to describe the design of a combination of an electric machine and an inverter for DDH systems. Based on the applications studied for DDH in [3, 5, 14], the ratings depicted in Table 1 are used as a baseline for sizing and designing an electric machine. The details regarding the electric machine and drive are discussed in the following sections.

Table 1: Rating of Electric Machine

\begin{tabular}{ll}
\hline Rated values & Value \\
\hline Rated speed, RPM & 2000 \\
Rated torque, Nm & 25 \\
Rated power, $\mathrm{kW}$ & 5.2 \\
\hline
\end{tabular}

\section{PERMAMENT MAGNET ELECTRIC MACHINES}

When selecting an electric motor for industrial and mobile applications, induction motors have been the standard choice due to their construction robustness and low cost. Nowadays, SPMSM are gaining a lot of attention for their superior efficiency and torque density compared to induction machines.

In this section, a SPMSM is proposed for highperformance electrification. The machine is designed to meet required frame size constraints and operate at the desired speed while maintaining high performance. The stator design must be carefully tuned to achieve high performance and fit reasonably small size, thus enabling to be used for electrifying hydraulic actuators.

\subsection{Stator Design Considerations}

A higher number of poles is desired to achieve higher torque density. However, machines with a higher number of poles typically use a higher number of stator slots to allocate the windings.

The function of the windings is to provide a sinusoidal magneto motive force (MMF) creating a rotating magnetic field. The magnets in the rotor will align with the stator rotating magnetic field, thus producing torque and making the rotor to spin. However, distributing the winding in a sinusoidal pattern in the stator is not practical. Alternatively, the winding can be distributed through the stator in such a way that a fundamental component of the rotating MMF is dominant compared to the rest of the harmonics.

In Figure 6 a distributed winding (DW) for 10 poles is shown. The dots and crosses depict where the current is coming into or leaving the stator plane. Typically, for a 3-phase machine, generating necessary poles in the stator magnetic field involves the winding being distributed to create a repeating square wave whose fundamental component matches that of the rotor. Hence, a 10-pole design requires 30 slots, which in limited volume will result in small slots to accommodate the copper wires. A higher number of slots and small slot area result in lower overall copper fill and higher stator resistance which leads to a decrease in the efficiency. Also, this kind of distributed windings requires large end windings, which makes the machine bulkier. 


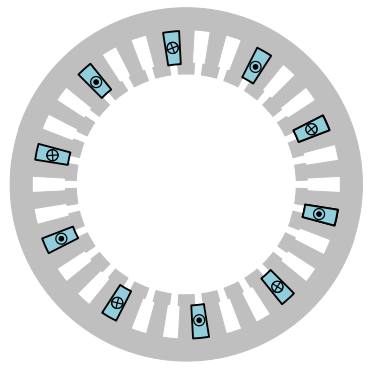

(a)

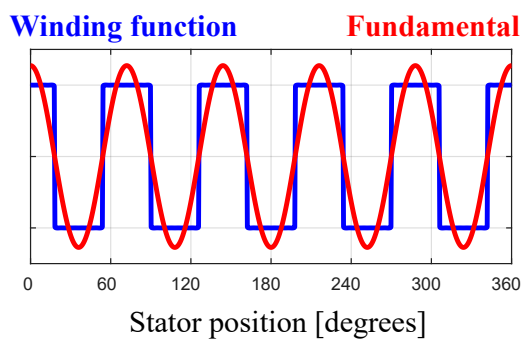

(b)

Figure 6: Distributed winding configuration, (a) Phase A windings, (b) winding function and fundamental

Alternatively, fractional slot concentrated windings (FSCW) [15-17], as shown in Figure 7, can be utilized in designs with a higher number of poles but limited stator volume. In this configuration the turns are distributed such that the dominant stator MMF harmonic matches the desired number of poles. It is to be noted that the dominant MMF harmonic is not necessarily the fundamental harmonic corresponding to the winding distribution.

The advantage of FSCW configuration is that rather than 30 slots, only 12 slots are needed, giving more room to allocate the coils in the stator teeth, thus decreasing the stator resistance. Also, as the coils are wrapped around each stator tooth, thus, the end windings are considerably shorter and require less volume compared to their distributed windings counterparts. The drawback of utilizing FSCW compared to DW is that for the same number of turns per phase the amplitude of the dominant harmonic component of the winding distribution is lower. Thus, more turns are needed to obtain a higher fundamental amplitude. Figure 8 shows the difference regarding space in between DW and FSCW, showing that FSCW is more compact and easier to manufacture.

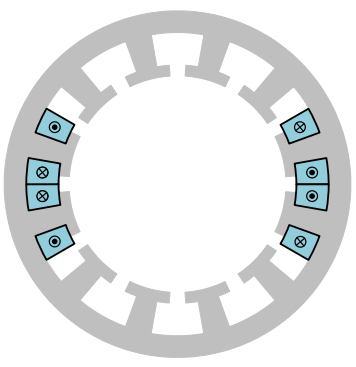

(a)

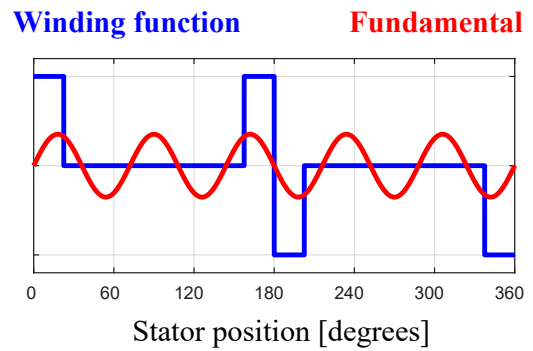

(b)

Figure 7: Fractional slot concentrated winding configuration, (a) Phase A windings, (b) winding function and dominant harmonic

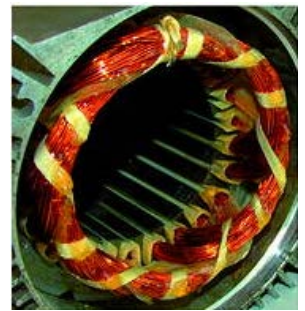

(a)

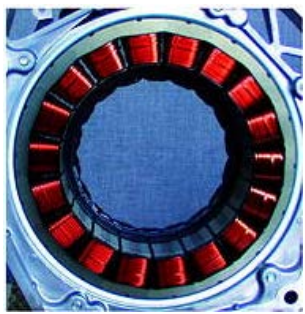

(b)
Figure 8: Comparison between stator winding configurations, (a) distributed winding, (b) fractional slot concentrated winding[18].

\subsection{Rotor Design Considerations}

Typically, for a surface PM rotor design, arc magnets are used in the rotor structure; however, in the proposed design, the magnets are shaped to decrease the ripple torque.

When a motor is designed for high-speed operation, then the rotor design becomes more challenging. However, this is not the case for hydraulic applications. As the machine is aimed to spin at 2000 RPM there are no additional structural requirements for the rotor design. 


\subsection{Proposed PM Electric Machine Design}

The geometric constraints for this machine consider an outer diameter of $150 \mathrm{~mm}$ and a shaft diameter of $60 \mathrm{~mm} .10$ poles were chosen for the design to take advantage of the low-speed requirement and minimize the stator back iron thickness. The rated values obtained from the design are shown in Table 2. Figure 9 shows the proposed design. Finite element analysis (FEA) was performed to obtain the torque waveform at rated conditions as shown in Figure 10. It can be seen that although the torque ripple increases slightly at overrated operation due to saturation effects, overall torque ripple is under $2 \%$ with a $0.5 \%$ ripple at rated operation (15 Arms).

An efficiency map is shown in Figure 11. In order to focus on the desired range of operation for this application, i.e. 300 to 3000 RPM and 5 to $25 \mathrm{Nm}$ of torque, the efficiency bands are limited to a lower bound of $80 \%$ in Figure 11. All the data below $80 \%$ is represented by a single color band. From the results it can be confirmed that high efficiency and minimal torque ripple can be achieved within the desired operation range from the designed electric machine.

Table 2: Rating of SPMSM proposed design

\begin{tabular}{ll}
\hline Rated value & Value \\
\hline Rated voltage, Vrms & 380 \\
Rated current, Arms & 15 \\
Number of poles & 10 \\
\hline
\end{tabular}

\section{Phase A \\ Phase B \\ Phase C \\ Iron \\ Magnet}

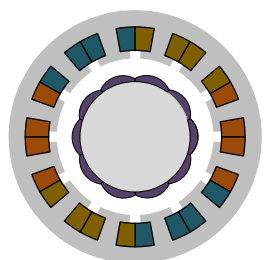

Figure 9: Proposed 12 slots/10 poles SPMSM design.

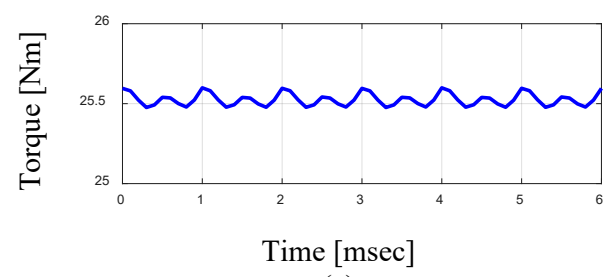

(a)

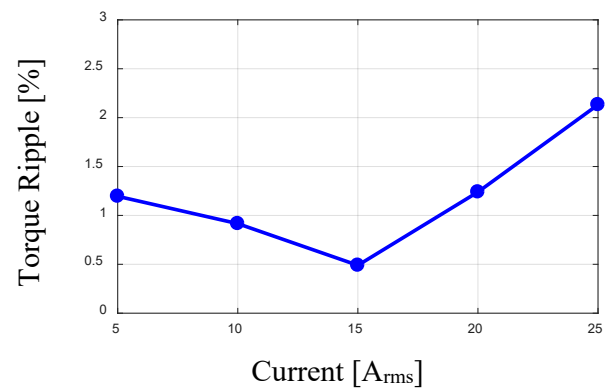

(b)

Figure 10: Shaft output (a) Torque at different current levels (b) Torque ripple percentage as a function of the stator current.

\section{INVERTERS}

An electric machine driven by variable speed drives (VSDs) provides higher efficiency and better dynamic performance than line-connected fixed speed electric machine. Depending on the types of the input power source, the VSDs can be classified into voltage-, current-, and impedancesource inverters, but the voltage-source inverter (VSI) has been playing a major role in industrial drive applications such as fan, blower, pump, and servo motors since the advent of insulated-gate bipolar transistors (IGBTs).

In this section, VSIs for electrified hydraulic actuators are introduced, and different switching device options are discussed in detail.

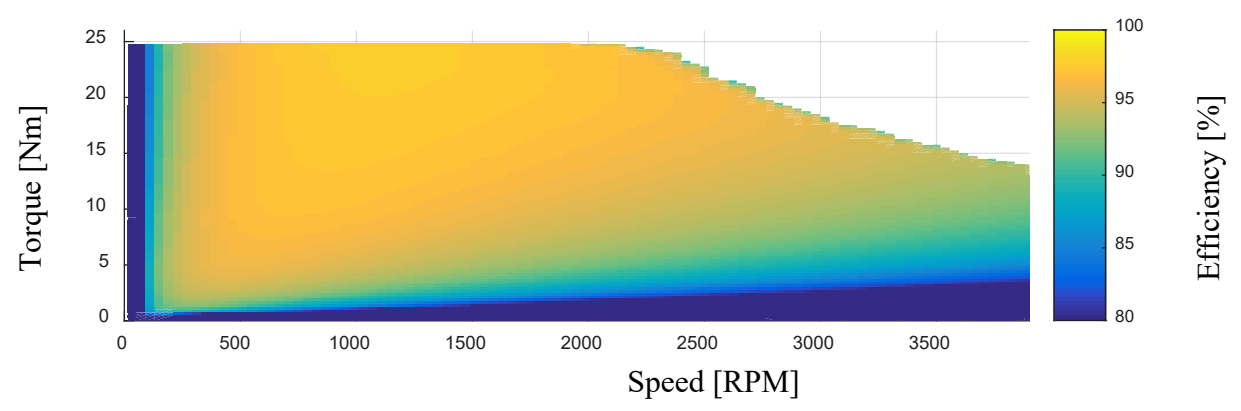

Figure 11: Efficiency map for proposed SPMSM machine with FSCW. 


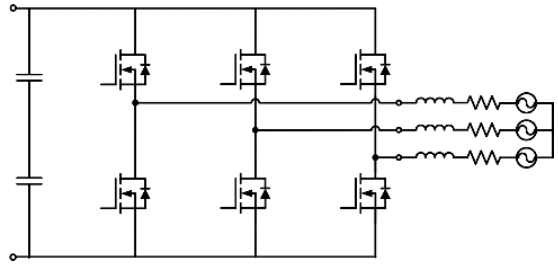

Figure 12: Schematic of 2-level voltage source inverter.

\subsection{Two-Level topology with IGBTs}

A 2-level VSI has been dominantly used for VSD applications, and it requires a dc-link capacitor, six active switches, and six antiparallel diodes as shown in Figure 12. The voltage ratings of the power devices and capacitors need to meet the rated voltage of the electric machine designed in the previous section. Since the rated line-to-line rms voltage of the electric machine is $380 \mathrm{~V}$, the peak phase voltage becomes $310.27 \mathrm{~V}$. When space vector modulation (SVM) as shown in Figure 13 is utilized the maximum peak inverter output voltage is $57.7 \%$ of the dc-link voltage indicating that the minimum required dc-link voltage is $537.7 \mathrm{~V}$. For higher than $550 \mathrm{~V}$ dc-link voltage and $15 \mathrm{~A}$ rated current, $900 \mathrm{~V}$ silicon $(\mathrm{Si})$ IGBT, SiC, and GaN devices are all applicable, and $1200 \mathrm{~V}$ Si IGBT and SiC are also available in the market.

Si IGBTs have been around more than three decades in power electronics industry [19], and their device characteristics and behavioral models are well understood. The price of the device is two to three times lower than the equivalent $\mathrm{SiC}$ or $\mathrm{GaN}$ devices as of 2019 [19], and there are large collections of device ratings and manufacturers. However, it is also wellknown fact that IGBTs can only operate within limited switching frequency range (typically less than $20 \mathrm{kHz}$ ) due to excessive switching losses. It also generates high conduction loss, which significantly affects the motor drive system efficiency at light load conditions.

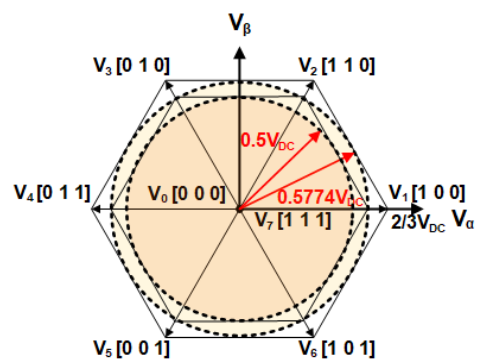

Figure 13: Vector diagram of space vector modulation and sine PWM.

\subsection{Two-Level topology with wide bandgap devices}

The $\mathrm{SiC}$ and $\mathrm{GaN}$ devices are alternative options to Si IGBTs. These devices can operate over 50 $\mathrm{kHz}$ due to its 5 to 10 times faster switching speed and lower on-state resistance. The increased cost due to high device price can ultimately compensated by reduced passive component [20], minimized cooling component design such as heatsink and fan [21], and energy-saving from improved efficiency throughout the operating time [22].

A circuit simulation is conducted to validate the impact of switching frequency on the current waveform as shown in Figure 14 and Figure 15. The dc-link voltage is set to be $600 \mathrm{~V}$ and $\mathrm{SiC}$ MOSFET C2M0080120D, which has a maximum blocking voltage of $1200 \mathrm{~V}$ and a current rating of $36 \mathrm{~A}$ is used for the simulation. The output current ripple is reduced by $60 \%$ in 50 $\mathrm{kHz}$ operation as compared to that of $20 \mathrm{kHz}$ operation. The reduced output current ripple leads to low PWM-induced iron losses [23], low ripple torque [24], and low audible noise.

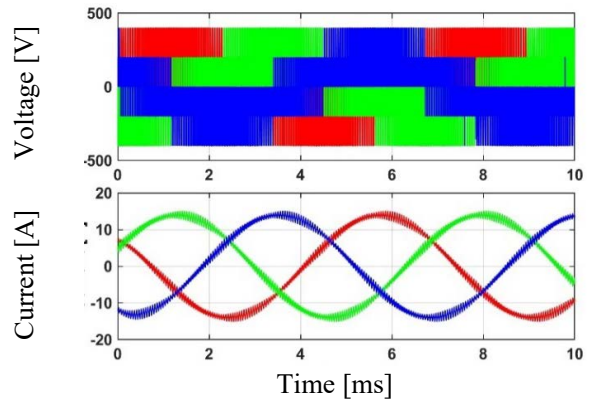

Figure 14: $\mathrm{SiC}$ inverter operating at $20 \mathrm{kHz}$ with $\mathrm{RL}$ load at $150 \mathrm{~Hz}$ fundamental frequency. 


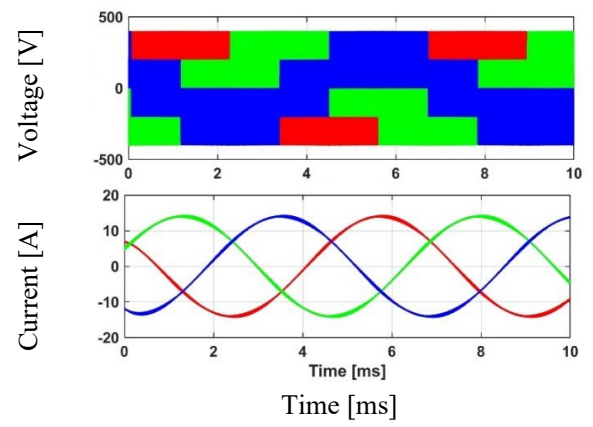

Figure 15: $\mathrm{SiC}$ inverter operating at $50 \mathrm{kHz}$ with $\mathrm{RL}$ load at $150 \mathrm{~Hz}$ fundamental frequency.

\section{DISCUSSION}

The benefits of electric drives allow to improve efficiency of hydraulic systems by implementing DDH. Hydraulic pumps typically operate in a range between 300 to 3000 RPM [25]. In the $\mathrm{DDH}$, the electric drive is directly connected to the pump where both the pump and the electric motor operate at the same speed. For a range where the operational speed varies between 300 through 3000 RPM the designed electric motor demonstrates a large efficiency, i.e. above $95 \%$. The efficiency only drops in low torque operation points that are unlikely to occur due to the pump operational characteristics [25].

Regarding controllability, the torque control in an electric drive is very high due to the capability of the inverter to inject current in the stator windings instantaneously. As the torque is mainly dependent in the injected current from the inverter, torque can be achieved extremely fast at any operational speed, thus making the electric drive suitable for deliver torque with good accuracy including the low speed or zero speed region. This last property makes inverter driven motors suitable for electrifying hydraulic systems where the low or zero speed operation can be a challenge otherwise.

Efficiency improvements were obtained when moving from valve-controlled to pumpcontrolled systems due to high performance servo drive. Moreover, direct-driven hydraulic systems are accepted as a promising technology for hydraulic hybridization which reduces the number of components and the size the overall system.
In terms of electric machines, SPMSM shows superior performance compared to induction machines. Thus, SPMSM was chosen for analysis for the electrification of a hydraulic system. For DDH applications, relatively low speeds, high torque, and limited size are the requirements while keeping the efficiency high. As machines with higher torque require typically more number of poles, a FSCW topology was chosen, thus being able to create the necessary number of poles, to match the torque needed in the limited volume constraint. The designed machine was analyzed with FEA showing efficiency above $95 \%$ in almost all the range of operation.

Finally, regarding the inverter, it was shown that higher switching frequencies can lead to small components and better performance in terms of torque and current ripple. However, high-switching frequencies are not achievable with IGBT switches. In this paper, it is proposed to use $\mathrm{SiC}$ switches that allow to increase the switching frequency and reduce the switching losses, thus, contributing to higher performance and efficiency.

\section{CONCLUSIONS}

In this paper, electrification of working hydraulics for off-road machinery application was discussed. The review in electrification of hydraulic system has demonstrated that significant improvements regarding efficiency were achieved by including electric drives.

Surface PM motor with FSCW and SiC-based power electronic inverter were designed and shown as a promising candidate for highperformance and high-power density pumpcontrolled systems as a way for further electrification of off-road machinery. Features of the propose system include high overall efficiency, compactness, and fast torque response.

\section{ACKNOWLEDGEMENT}

The authors would like to thank to the Wisconsin Electric Machines and Power Electronic Consortium for their support. Also, authors would like to acknowledge JSOL for providing the license for their software JMAG for finite element analysis. 


\section{REFERENCES}

[1] Wang J, Yang Z, Liu S, et al (2016) A comprehensive overview of hybrid construction machinery. Adv Mech Eng 8:1-15. https://doi.org/10.1177/1687814016636809

[2] Casoli P, Riccò L, Campanini F, Bedotti A (2016) Hydraulic Hybrid Excavator-mathematical model validation and energy analysis. Energies 9:1002. https://doi.org/10.3390/en9121002

[3] Teemu K, Kauranne H, Calonius O, et al (2018) Experimental investigation of a directly hydraulic unit in an industrial application. 11 Int Fluid Konf. https://doi.org/10.18154/RWTH-2018-224644

[4] Koitto T, Calonius O, Kauranne H, et al (2018) Enhanced energy efficiency of industrial application by direct driven hydraulic unit. 2018 Glob Fluid Power Soc PhD Symp GFPS 2018 16. https://doi.org/10.1109/GFPS.2018.8472365

[5] Koitto T, Kauranne H, Calonius O, et al (2019) Experimental study on fast and energy-efficient direct driven hydraulic actuator unit. Energies 12:1-17. https://doi.org/10.3390/en12081538

[6] Edamura M, Ishida S, Imura S, Izumi S (2013) Adoption of electrification and hybrid drive for more energy-efficient construction machinery. Hitachi Rev 62:118-122

[7] Lin T, Wang Q, Hu B, Gong W (2010) Research on the energy regeneration systems for hybrid hydraulic excavators. Autom Constr 19:10161026.https://doi.org/10.1016/j.autcon.2010.08.002

[8] Ho TH, Ahn KK (2012) Design and control of a closed-loop hydraulic energy-regenerative system. Autom Constr 22:444-458. https://doi.org/10.1016/j.autcon.2011.11.004

[9] Wang T, Wang Q (2014) An energy-saving pressurecompensated hydraulic system with electrical approach. IEEE/ASME Trans Mechatronics 19:570 578. https://doi.org/10.1109/TMECH.2013.2250296

[10] Joo C, Stangl M (2016) Application of power regenerative boom system to excavator. 10th Int Fluid Power Conf 7-11

[11] Vukovic M, Sgro S, Murrenhoff H (2013) Steam - A mobile hydraulic system with engine integration. ASME/BATH 2013 Symp Fluid Power Motion Control FPMC 2013 1-11. https://doi.org/10.1115/FPMC20134408

[12] Kim YB, Kim PY, Murrenhoff H (2016) Boom potential energy regeneration scheme for hydraulic excavators. BATH/ASME 2016 Symp Fluid Power Motion Control FPMC 2016 1-7. https://doi.org/10.1115/FPMC2016-1740

[13] Niraula A, Zhang S, Minav T, Pietola M (2018) Effect of zonal hydraulics on energy consumption and boom structure of a micro-excavator. Energies 11:1-22. https://doi.org/10.3390/en11082088

[14] Hänninen H, Minav T, Pietola M (2016) Replacing a constant pressure valve controlled system with a Pump controlled system. BATH/ASME 2016 Symp Fluid Power Motion Control FPMC 20161 7. https://doi.org/10.1115/FPMC2016-1777
[15] Wang A, Wang C, Wang Y (2013) Performance analysis and comparison of interior permanent magnet machine with FSCW and distributed windings for a hybrid electric vehicle. In: International Conference on Electrical Machines and Systems, ICEMS. IEEE Computer Society, pp 1044-1047

[16] Cheng L, Wang M, Zheng P, et al (2018) Improvement of a Hybrid-PM Interior-PMSM with Six-Phase FSCW for EV Application. In: ICEMS 2018 - 2018 21st International Conference on Electrical Machines and Systems. Institute of Electrical and Electronics Engineers Inc., pp 425429

[17] Li J, Zou J, Xu Y (2015) Analysis and design of FSCW SPM machines for a given constant power region. In: 2015 IEEE International Magnetics Conference, INTERMAG. Institute of Electrical and Electronics Engineers Inc.

[18] Single-tooth motors could bite into the EV market - Drives and Controls Magazine. https://drivesncontrols.com/news/fullstory.php/a id/4009/Singletooth motors could bite into the EV market. html. Accessed 14 Nov $2 \overline{0} 19$

[19] Baliga BJ (2018) Fundamentals of power semiconductor devices, Second edition. SPRINGER-VERLAG NEW YORK

[20] Burkart RM, Kolar JW (2017) Comparative life cycle cost analysis of Si and SiC PV converter systems based on advanced $\eta-\rho-\sigma$ multiobjective optimization Techniques. IEEE Trans Power Electron 32:4344 4358. https://doi.org/10.1109/TPEL.2016.2599818

[21] Murakami Y, TajimaY,Tanimoto S(2013)Air-cooled full$\mathrm{SiC}$ high power density inverter unit. World Electr Veh J 6:669-672. https://doi.org/10.1109/EVS.2013.6914864

[22] Power America_Department of Energy

[23] Chang L, Jahn̄s TM (2018) Prediction and evaluation of PWM-induced current ripple in IPM machines incorporating slotting, saturation, and cross-coupling effects. IEEE Trans Ind Appl 54:6015-6026. https://doi.org/10.1109/TIA.2018.2846718

[24] Shirabe K, Swamy M, Kang JK, et al (2012) Advantages of high frequency PWM in AC motor drive applications. In: 2012 IEEE Energy Conversion Congress and Exposition, ECCE 2012. pp 2977-2984

[25] Majumdar SR (2003) Oil hydraulic systems: principles and maintenance. McGraw-Hill, New York, pp. 98 